\title{
COMPETITIVIDADE E \\ DESENVOLVIMENTO: UM ESTUDO EM \\ DESTINOS INDUTORES DO TURISMO \\ BRASILEIRO
}

\author{
COMPETITIVENESS AND DEVELOPMENT: A STUDY OF TOURISM INDUCTOR DESTINATIONS IN \\ BRAZIL
}

\author{
COMPETITIVIDAD Y DESARROLLO: UN ESTUDIO EN DESTINOS INDUCTORES DEL TURISMO \\ BRASILEÑO
}

Daniel Pires Vieira

Doutorando

Universidade de Brasília

vieira.pires@gmail.com

Valmir Emil Hoffmann

Doutor

Universidade de Brasília

ehoffmann@unb.br

Submetido em: 11/03/2013

Aprovado em: 01/07/2013

RESUMO

O estudo da competitividade em destinos turísticos traz o desafio de uma visão sistêmica, uma vez que o desenvolvimento bem-sucedido do destino não se estabelece somente com fatores presentes no nível empresarial, sendo necessários aspectos do entorno social do destino. Partindo dessa perspectiva, os principais modelos de competitividade de destinos turísticos convergem ao tratar a competitividade como etapa intermediária para o objetivo final: o desenvolvimento local. O presente estudo objetiva analisar a relação entre competitividade de destinos e desenvolvimento e identificar quais dimensões da competitividade são influentes para o desenvolvimento local. A pesquisa abrange 65 destinos brasileiros e caracteriza-se como exploratória e descritiva com aplicação de métodos quantitativos. São empregadas análise fatorial, regressões multivariadas e análises de correlação. Os resultados demonstram que aspectos relacionados à gestão dos destinos turísticos são centrais para que a competitividade possa gerar resultados positivos para o desenvolvimento local.

PALAVRAS-ChAVE: Competitividade. Competitividade Sistêmica. Turismo.

\section{ABSTRACT}

The analysis of competitiveness of a destination brings with it the challenge of a systemic approach, given that the successful development of a destination is not only established based on factors present at the entrepreneurial level, but also requires aspects from to the social environment. Based on this perspective, the main models for destination competitiveness analysis converge to view competitiveness as an intermediate step toward the ultimate goal: local development. This study analyzes the relationship between development and competitiveness of destinations, and identifies which dimensions of competitiveness are influential to local development. The research covers sixty-five Brazilian destinations, and is characterized as exploratory and descriptive, with the application of quantitative methods. Factor analysis, multivariate 
regression and correlation analysis are used to achieve the objective. The results show that aspects related to the management of a destination's competitiveness have a positive influence on local development.

KEY-WORDS: Competitiveness. Systemic Competitiveness. Tourism.

\section{RESUMEN}

El estudio de la competitividad en destinos turísticos conlleva el desafío de una visión sistémica, ya que el desarrollo exitoso del destino no se establece solamente con factores presentes a nivel empresarial, sino que son necesarios aspectos del entorno social del destino. Partiendo de esa perspectiva, los principales modelos de competitividad de destinos turísticos convergen al tratar la competitividad como una etapa intermedia para el objetivo final: el desarrollo local. El presente estudio intenta analizar la relación entre la competitividad de los destinos y el desarrollo e identificar las dimensiones de la competitividad que influyen sobre el desarrollo local. La investigación abarca 65 destinos brasileños y se caracteriza como exploratoria y descriptiva, con aplicación de métodos cuantitativos. Se utiliza análisis factorial, regresiones multivariadas y análisis de correlación. Los resultados demuestran que los aspectos relacionados a la gestión de los destinos turísticos son centrales para que la competitividad pueda generar resultados positivos para el desarrollo local.

PALABRAS ClAVE: Competitividad. Competitividad Sistémica. Turismo.

\section{INTRODUÇÃO}

Destinos turísticos são compreendidos por Buhalis (2000) como áreas geográficas definidas que oferecem um conjunto de produtos e serviços turísticos integrados que serão comercializados e consumidos pelos turistas sob a marca comum do destino. Em vista da complexidade, da heterogeneidade e da complementaridade das atividades econômicas que compõem os serviços prestados ao turista, a competitividade de um destino turístico não pode ser avaliada a partir de uma única atividade econômica. A análise da competitividade de destinos turísticos traz consigo a necessidade e o desafio de uma visão abrangente que considere os diversos fatores que direta ou indiretamente influenciam o seu desempenho.

No Brasil o estudo da competitividade de destinos turísticos vem ganhando importância a partir do diagnóstico realizado pelo Ministério do Turismo - MTur, presente no Plano Nacional de Turismo 20032007, que aponta a falta de estruturação do setor turístico como a causa de sua baixa competitividade (COSTA; HOFFMANN, 2006). Em que pese sua importância, a competitividade dos destinos turísticos é tida como um objetivo intermediário, para o objetivo final que seria o desenvolvimento econômico e social da população local (PORTER, 1990; CROUCH; RITCHIE, 1999; HEATH, 2003; DWYER; KIM, 2003). Tal suposição, embora presente nos modelos, conta com poucos estudos que visam verificá-la. Dessa forma, uma boa medida da adequação do modelo de competitividade poderia ser sua capacidade de se relacionar com ou de predizer o desenvolvimento econômico.

Hassan (2000) destaca que no estudo da competitividade de destinos turísticos é crítico o desenvolvimento de uma base de conhecimento a respeito de quais fatores são determinantes para a competitividade. Para Crouch (2011), os modelos de competitividade de destinos turísticos alcançaram uma boa base na qual se identificam os atributos que estão relacionados à competitividade sem, entretanto, relacionar quais deles são determinantes para a competitividade desses destinos. O autor ressalta ainda que vários aspectos podem ser importantes para a competitividade de um destino, mas somente alguns serão determinantes. Pode-se inferir aqui uma aproximação ao argumento de Barney (1991) ao discutir a Visão Baseada em Recursos - VBR - em que afirma que um recurso para gerar vantagem competitiva deve ser: raro, valioso, imperfeitamente imitável ou não possuir substitutos estratégicos. Dessa forma, uma característica presente em diversos destinos pode ser importante para a competitividade, porém não será o seu determinante. 
Considerando os argumentos propostos, o objetivo do presente trabalho é analisar a relação entre a competitividade de destinos turísticos e o desenvolvimento local e identificar as dimensões da competitividade que são influentes para o desenvolvimento dos destinos turísticos. Para a consecução desses objetivos, o trabalho encontra-se dividido em, além desta, outras 4 seções. Na seção seguinte, é realizada uma breve revisão da literatura sobre competitividade e competitividade de destinos turísticos que orientará as análises a serem realizadas. A terceira seção é dedicada ao método empregado e descreve as variáveis e as técnicas de análise utilizadas. Na quarta seção são apresentados os resultados e na última seção são traçadas as conclusões e são identificadas as limitações do presente trabalho.

\section{REFERENCIAL}

As primeiras abordagens sobre competitividade têm suas origens na literatura sobre gerenciamento estratégico, sendo inicialmente tratada partindo de uma perspectiva exógena à empresa, de forma que as estratégias competitivas eram determinadas por fatores ambientais (FURRER; THOMAS; GOUSSEVKAIA, 2008). Porter (1986) fez uma das mais influentes contribuições para o campo ao fornecer um modelo de análise da competitividade da empresa baseada na estrutura da indústria e não na firma individual (VASCONCELOS; CYRINO, 2000; BERTERO; VASCONCELOS; BINDER, 2002; FURRER; THOMAS; GOUSSEVKAIA, 2008), que foi inicialmente aplicado a uma diversa gama de indústrias (CAMPBELL-HUNT, 2000). Baseado no Modelo da Estrutura - Conduta - Performance, o modelo proposto por Porter (1986) estabelece que a intensidade da concorrência em uma indústria é determinada por cinco forças competitivas: rivalidade existente entre competidores, ameaça de substituição, poder de negociação dos compradores, poder de negociação dos fornecedores e ameaça de entrada de novos competidores. Todas as empresas inseridas em uma mesma indústria estariam sujeitas às mesmas forças e quanto maior a concorrência dessa indústria, menores os retornos para as empresas.

A principal crítica apresentadas ao modelo de Porter (1986) aponta no sentido de que sua perspectiva de análise foca exclusivamente o ambiente em que a empresa se insere, ignorando seus aspectos internos. O modelo das cinco forças competitivas parte do pressuposto de que os atributos e os recursos disponíveis para empresas inseridas em uma mesma indústria são idênticos (BARNEY, 1991), sendo que as características internas das empresas ocupariam um papel secundário nas análises realizadas (VASCONCELOS; CYRINO, 2000). Essa crítica encontra seu embasamento na VBR. Embora tal abordagem possa ser compreendida como complementar ao modelo das cinco forças de Porter (BARNEY, 1991; CARNEIRO; CAVALCANTE; SILVA, 1997), ela parte de um pressuposto diferente: as empresas são heterogêneas (BARNEY, 1991; COYNE, 1986; PETERAF, 1993). A VBR examina a relação existente entre as características internas da firma (seus recursos) e o seu desempenho (DIERICKX; COOL, 1989; BARNEY, 1991; VASCONCELOS; CYRINO, 2000; FURRER; THOMAS; GOUSSEVKAIA, 2008).

Recursos, para essa abordagem, podem ser entendidos como ativos tangíveis e intangíveis controlados por uma firma e que podem ser usados para criar e implementar estratégias (BARNEY; HESTERLY, 2011). A vantagem competitiva, segundo a VBR, seria alcançada pela empresa ao implementar uma estratégia única, não adotada por qualquer empresa concorrente, seja atual ou potencial. A sustentabilidade da vantagem competitiva derivaria da capacidade ou não da concorrência em duplicar essa estratégia (DIERICKX; COOL, 1989; BARNEY, 1991; GRANT, 1991; HOFFMAN 2000). A fonte da vantagem competitiva se encontra nos recursos e nas competências desenvolvidos e controlados pelas firmas, de forma que deve haver recursos capazes de gerar um desempenho superior e que seriam naturalmente limitados (PETERAF, 1993; VASCONCELOS; CYRINO, 2000).

Barney (1991) argumenta que nem todas as empresas possuem recursos com capacidade de proporcionar vantagens competitivas e que um recurso para ser capaz de gerar vantagens competitivas deve possuir quatro características: serem raros, valiosos, imperfeitamente imitáveis e não possuírem substitutos estratégicos equivalentes. De forma complementar, outros aspectos necessários para a geração e para a manutenção de vantagens competitivas são identificados (COYNE, 1986; DIERICKX; COOL, 1989; PETERAF, 1993; HOFFMAN, 2000) e podem ser compreendidos como mecanismos de proteção das vantagens competitivas e das rendas superiores geradas (VASCONCELOS; CYRINO, 2000). 
Peteraf (1993) destaca outros quatro critérios relacionados e necessários para a existência e para a manutenção de vantagens competitivas sustentáveis: limites ex-ante e ex-post para competição, mobilidade imperfeita de fatores e heterogeneidade dos recursos. Os limites ex-ante e ex-post para a competição relacionam-se à possibilidade de aquisição de vantagens competitivas e sua manutenção, considerando que o excesso de competição no mercado dissiparia os retornos da firma. A mobilidade imperfeita estaria, assim como a heterogeneidade dos recursos, relacionada à possibilidade de obtenção e manutenção das chamadas rendas ricardianas (GRANT, 1991; PETERAF 1993; VASCONCELOS; CYRINO 2000). Caso os recursos estivessem distribuídos de forma homogênea ou fossem perfeitamente móveis, seria impossível a manutenção de vantagens competitivas (BARNEY 1991; GRANT, 1991; PETERAF, 1993). Embora estabeleça interpretações diferentes, as proposições de Peteraf (1993) são bem próximas às de Barney (1991) ao tratar dos recursos que proporcionam vantagens competitivas.

Ao tratar da possibilidade de imitação por parte da concorrência, Dierickx e Cool (1989) apontam a existência de recursos que não são comercializáveis, tais como: a reputação, a lealdade de consumidores e de fornecedores, as capacidades e as habilidades específicas desenvolvidas por uma firma, entre outros. Teece, Pisano e Shuen (1997) ressaltam que alguns recursos são difíceis de serem transferidos ou imitados por conterem conhecimentos tácitos envolvidos. Na impossibilidade de aquisição de um fator, a alternativa que a concorrência dispõe seria sua produção interna (WERNERFELT, 1984). No entanto, devido ao tempo ou aos custos necessários para acumular os recursos, aos fatores históricos para seu desenvolvimento (DIERICKX; COOL, 1989; BARNEY, 1991; PETERAF, 1993; TEECE; PISANO; SHUEN, 1997), ou mesmo à incapacidade de se determinar quais recursos estratégicos são determinantes para a vantagem competitiva (BARNEY, 1991), nem sempre essa alternativa mostra-se factível.

Coyne (1986), por sua vez, ressalta o papel desempenhado pela demanda ao estabelecer que uma vantagem competitiva sustentável é obtida quando três condições distintas são alcançadas: os consumidores percebem uma diferença consistente entre os atributos dos produtos da empresa e os da concorrência; essa diferenciação é resultado de uma lacuna de capacidade entre a empresa e a concorrência; e essas duas distinções são duradouras. Dessa forma, vantagens competitivas derivam de desigualdades entre competidores, sendo que essas devem ser percebidas pelo mercado, ou seja, devem refletir em algum critério que influencie a decisão de compra (COYNE, 1986; HOFFMAN, 2000).

Dierickx e Cool (1989) argumentam que os ativos necessários para a obtenção de uma vantagem competitiva são cumulativos e variáveis ao longo do tempo. Partindo dessa premissa, os autores tentam dotar a análise das vantagens competitivas baseada em recursos de alguma dinâmica, fugindo da análise estática inicialmente proposta pela VBR. Vasconcelos e Cyrino (2000) ressaltam que, com o ambiente dinâmico, as firmas devem buscar recursos que mantenham seu desempenho e Ihes garantam a sobrevivência. A perspectiva do ambiente e dos recursos, ambos estáticos na VBR, representam uma de suas principais limitações (VASCONCELOS; CYRINO, 2000).

Meyer-Stamer (2001) afirma que o desenvolvimento industrial bem-sucedido não se estabelece somente com fatores presentes no nível empresarial ou com condições presentes no nível macroeconômico e destaca que é necessária ainda a articulação de organizações públicas e privadas em diversos níveis. Esser et al. (1996) destacam que a competitividade não pode ser explicada exclusivamente pela perspectiva centrada no nível empresarial e estabelecem dois critérios complementares para a competitividade das empresas: estarem submetidas à competição com outras empresas de forma a buscarem aprimorar seus produtos; e estarem localizadas em redes articuladas que potencializem e apoiem os seus esforços. Enfatiza-se, assim, a necessidade de um entorno eficaz e da complementaridade entre competição e cooperação para a criação de competitividade.

Partindo dessas considerações, Esser et al. (1996) propõem o Modelo de Competitividade Sistêmica. Tal modelo decompõe a análise da competitividade, seja local ou nacional, em quatro níveis de análise distintos, porém relacionados: meta, fatores de integração social de forma a assegurar a coordenação entre os diferentes níveis; macro, corresponde à geração de políticas públicas e à manutenção da estabilidade do ambiente macroeconômico; meso, vinculado a fatores capazes de gerar em entorno apto a fomentar, multiplicar e os esforços das empresas (redes de associação e cooperação); e micro, associado aos aspectos internos e ao entorno imediato das empresas (ESSER et al., 1996). De forma similar, Meyer-Stamer (2001) estabelece os mesmos níveis de análise nos seguintes termos: nível meta - padrões de organização política e econômica 
voltados para o desenvolvimento; nível macro - ambiente econômico, político e legal; nível meso políticas específicas para a criação de uma vantagem competitiva; e nível micro - atividades dentro da empresa e da cooperação formal e informal para criação de vantagens competitivas.

O Modelo de Competitividade Sistêmica atenderia à necessidade de ampliação do conceito de competitividade (COSTA; HOFFMANN, 2006). A avaliação da competitividade em uma perspectiva sistêmica envolve uma percepção mais ampla sobre o meio em que a empresa se insere e considera aspectos como: as diretrizes dos governos em distintas esferas, a interação da empresa com seu ambiente e a coordenação de atividades conjuntas, tanto por parte do governo quanto da iniciativa privada (HOFFMANN; COSTA; BATAGLIA, 2010). Tal modelo oferece uma alternativa à VBR, bem como ao modelo de Porter (1990) (HOFFMANN; COSTA; BATAGLIA, 2010), uma vez que foca as decisões conjuntas à interação de agentes em diferentes níveis da economia (COSTA; HOFFMANN, 2006). Bertero, Vasconcelos e Binder (2003) destacam que, para a abordagem sistêmica, a estratégia reflete os sistemas sociais específicos em que ela encontra-se inserida.

Nota-se, assim, uma evolução no conceito de vantagem competitiva. Inicialmente focado na performance da empresa a partir das características da indústria em que ela se insere ou nos recursos e nas capacidades que ela dispõe, passando para um modelo de análise da competitividade que abrange as características do entorno social da empresa. Nesse sentido, a competitividade envolve não só as organizações diretamente vinculadas ao processo produtivo, mas o conjunto de relacionamentos capazes de fomentar sinergias e promover a competitividade e o desenvolvimento tanto para empresas quanto para a região ou para o país. Os modelos de avaliação de competitividade de destinos turísticos seguem essa perspectiva não só pela diversidade de indústrias envolvidas no setor (HASSAN, 2000), mas pela necessidade de se implicar na análise os diferentes atores sociais que direta ou indiretamente sofrem os impactos do desenvolvimento da atividade e por demandar colaboração e cooperação dos diferentes níveis de forma a competirem de forma efetiva (CROUCH; RITCHIE, 1999).

A vantagem competitiva de um destino turístico não conta com uma definição amplamente aceita (CROUCH; RITCHIE, 1999). Algumas definições apontam no sentido da capacidade do destino criar novos produtos que agreguem valor aos seus recursos e mantenham seu posicionamento no mercado em relação aos seus competidores (HASSAN, 2000). Outras descrevem no sentido da atratividade do destino e da singularidade da experiência proporcionada na competitividade do destino turístico (CROUCH; RITCHIE, 1999; DWYER; KIM, 2003). Para Ritchie e Crouch (2010), a competitividade de um destino relaciona-se à eficiência e à efetividade que seus recursos são empregados de forma a gerar crescimento e desenvolvimento no setor turístico. Os conceitos de vantagem competitiva e vantagem comparativa proporcionam a base para o desenvolvimento dos modelos de competitividade de destinos turísticos (CROUCH; RITCHIE, 1999).

O Modelo de Calgary, proposto por Crouch e Ritchie (1999), parte de uma perspectiva sistêmica e associa o conceito de competitividade de um destino turístico à sua capacidade de contribuir para a economia local e para o aumento da qualidade de vida da população. O sucesso da atividade turística não pode ser analisado de forma isolada, uma vez que está diretamente relacionado ao desempenho de organizações e de outros setores econômicos, tais como: energia, transportes e telecomunicações, e sociais, como: governo, empresas, organizações não governamentais, associações. Para serem bem-sucedidos, os destinos turísticos devem assegurar sua atratividade e a singularidade das experiências proporcionadas aos seus visitantes (CROUCH; RITCHIE, 1999).

Segundo o modelo proposto por Crouch e Ritchie (1999), a competitividade de um destino turístico é resultado do relacionamento de quatro Dimensões (Recursos Centrais e Atrativos, Fatores de Suporte e Recursos, Gestão do Destino e Determinantes Qualificadores) influenciadas por aspectos macro e microambientes. Os aspectos macroambientais representam as possíveis externalidades (ambientais, políticas, econômicas) às quais o destino turístico encontra-se susceptível. Os aspectos competitivos microambientais são representados pelo setor empresarial turístico do destino, além de órgãos públicos presentes no destino, seus stakeholders e outros mercados turísticos competidores. As Dimensões do Modelo são descritas por Crouch e Ritchie (1999) da seguinte forma: (i) Recursos Centrais e Atrativos; (ii) Fatores de Suporte e Recursos; (iii) Gestão do Destino; e (iv) Determinantes Qualificadores. Cumpre destacar que o Modelo de Calgary continuou a ser desenvolvido e foi integrada uma quinta dimensão: Políticas e Planejamento, o que contribuiu para expandir a quantidade de componentes analisados.

Crouch e Ritchie (1999) reconhecem que seu modelo não é preditivo, tampouco causal. Tratase de um modelo conceitual que ainda requer maiores desenvolvimentos de forma a possibilitar 
sua generalização. Entre suas principais limitações, pode-se citar: a dificuldade de se mensurar os componentes devido à falta de informações estatísticas em vários destinos e a falta de uma ordem de importância entre os componentes e as variáveis que os compõem (CROUCH; RITCHIE, 1999; TABERNER, 2007). Costa e Hoffmann (2006) destacam que o modelo proposto apresenta um salto qualitativo na construção de um modelo de competitividade, porém ainda se mostra limitado para aplicação empírica pela ausência de indicadores. Embora os autores enfatizem que o desenvolvimento da competitividade deva resultar na melhoria do bem-estar da população local, eles não apresentam evidências desse relacionamento.

Também partindo de uma perspectiva sistêmica, Dwyer e Kim (2003) propõem um modelo para a avaliação da competitividade de destinos turísticos contendo diversas variáveis inicialmente identificadas por Crouch e Ritchie (1999). O Modelo Integrado de Dwyer e Kim (2003), no entanto, diferencia-se por ter estabelecido um relacionamento mais claro entre as variáveis, além de propor um conjunto de possíveis indicadores para as variáveis do modelo, o que representa um avanço em relação a uma das limitações encontradas no modelo de Crouch e Ritchie (1999). O modelo de Dwyer e Kim (2003) conta com quatro dimensões: Recursos, Gestão do Destino, Condições Situacionais e Condições de Demanda. Tais dimensões contribuiriam direta ou indiretamente para a competitividade do destino, que seria um objetivo intermediário para o resultado final pretendido: a prosperidade socioeconômica.

A dimensão Recursos encontra-se subdividida em três subcategorias: Recursos Inatos (naturais e herdados), Recursos de Apoio e Recursos Criados. O Modelo demonstra que os Recursos não são capazes de influenciar diretamente a competitividade do destino, sendo dependentes das outras categorias e dimensões para tanto. Seguindo o disposto no Modelo, nota-se que os recursos relacionados à vantagem comparativa (recursos inatos, naturais e herdados) de forma isolada sequer conseguem influenciar as demais dimensões, sendo necessários os dois outros tipos de Recursos (de Apoio e Criados).

A dimensão Situações Condicionais corresponde à dimensão Determinantes Qualificadores identificada anteriormente por Crouch e Ritchie (1999), incluindo, no entanto, os aspectos macro e microambientes. A dimensão Gestão do Destino também encontra correspondência com a dimensão homônima do Modelo de Calgary, porém com a ressalva de que Dwyer e Kim (2003) distinguem o papel da gestão realizada pelo Governo do papel da gestão realizada pela indústria turística, ressaltando os aspectos de coordenação necessária não só entre governo e indústria, mas com a própria comunidade de forma a alcançar e manter a competitividade do destino. A dimensão Condições de Demanda enfatiza o papel da demanda na competitividade. Um destino pode ser competitivo ou não para determinado segmento, dependendo de suas motivações e expectativas sobre a viagem (DWYER; KIM, 2003). Outro ponto ressaltado pelos autores é o papel da demanda doméstica na competitividade ao oferecer condições para eficiências estáticas e encorajar melhorias e inovações (DWYER; KIM, 2003).

Entre as limitações identificadas por Dwyer e Kim (2003) ao modelo proposto, destacam-se a necessidade de maiores pesquisas sobre a importância relativa das diferentes dimensões e dos diferentes indicadores propostos e a necessidade de se integrarem indicadores subjetivos e objetivos na análise da competitividade. Uma das dificuldades do Modelo Integrado é a falta de indicadores que possibilitem a comparação ente diversos destinos. Destaque-se ainda que o Modelo Integrado, a exemplo do Modelo de Calgary, pressupõe a existência de uma relação positiva entre o desenvolvimento da competitividade de um destino turístico e sua prosperidade.

Considerando a necessidade de comparabilidade para avaliação da competitividade de destinos turísticos, Gooroochurn e Sugiyarto (2004) propuseram o Competitiveness Monitor em que, a partir de dados de organismos internacionais, a competitividade turística de diversos países é avaliada. De forma similar, o Fórum Econômico Mundial criou o Global Competitiveness Report e, desde 2007, começou a verificar também a competitividade turística dos países por meio do Travel and Tourism Competitiveness Report (FÓRUM ECONÔMICO MUNDIAL, 2011). Apesar de trabalharem com bases de informações abrangentes, ambos os modelos podem ser criticados pelo corte de análise adotado. Ao centrar suas análises em países, os modelos não conseguiriam distinguir as diferentes realidades existentes, o que, especialmente em países de grandes dimensões e com grande diversidade interna, tal como o Brasil, poderia gerar viés em suas análises. 
Com o intuito de orientar as políticas públicas para o desenvolvimento do setor turístico, o Ministério do Turismo realiza, desde 2008, pesquisas com objetivo de avaliar a competitividade de sessenta e cinco destinos nacionais. Para definição das macrodimensões e das dimensões utilizadas no estudo, definiu-se competitividade como: "a capacidade crescente de gerar negócios nas atividades econômicas relacionadas com o setor de turismo, de forma sustentável, proporcionando ao turista uma experiência positiva" (MINISTÉRIO DO TURISMO, 2008, p. 32). De forma a compor um índice de competitividade, para cada um dos destinos selecionados foram definidas cinco macrodimensões e treze dimensões para a construção dos índices de competitividade, sendo consideradas variáveis que permitissem a aferição das capacidades do destino direta e indiretamente relacionadas ao desenvolvimento da atividade turística (MINISTÉRIO DO TURISMO, 2008). O Estudo de Competitividade (MINISTÉRIO DO TURISMO, 2008) tem como uma de suas expectativas de que, com o aumento da competitividade, os destinos sejam capazes de distribuir os fluxos de turistas e dinamizar as economias do território em que se encontram inseridos. Pressupõe-se, assim, que a exemplo dos demais modelos, o aumento da competitividade teria influência sobre o desenvolvimento do destino e que uma boa medida da adequação do modelo de competitividade seria sua capacidade de se relacionar com ou de predizer o desenvolvimento econômico do destino turístico.

\section{MÉTODO DE PESQUISA}

Segundo a classificação proposta por Malhotra (2001), pode-se caracterizar a presente pesquisa como exploratória, uma vez que busca o levantamento de critérios para a maior compreensão sobre o problema estudado; e descritiva, dada a finalidade de descrição dos aspectos determinantes para a competitividade de destinos turísticos e suas consequências para o desenvolvimento socioeconômico. Adicionalmente a pesquisa caracteriza-se como dedutiva com a aplicação de técnicas quantitativas.

O universo estudado é composto por sessenta e cinco destinos turísticos selecionados pelo Ministério do Turismo como indutores do turismo nacional. Tais destinos distribuem-se por todas as regiões do país e por todas as unidades da federação e vêm sendo objeto de estudo para a aferição de sua competitividade turística desde 2008, por meio da aplicação do modelo de competitividade desenvolvido pelo MTur (MINISTÉRIO DO TURISMO, 2008; 2010). O Quadro 1 apresenta a relação de destinos analisados.

Quadro 1 - Lista de Destinos Turísticos

\begin{tabular}{|l|l|l|l|l|}
\hline UF - Destino & UF - Destino & UF - Destino & UF - Destino & UF - Destino \\
\hline AC - Rio Branco & CE - Fortaleza & MG - Ouro Preto & PI - Parnaíba & Ro - Porto Velho \\
\hline AL - Maceió & $\begin{array}{l}\text { CE - Jijoca de } \\
\text { Jericoacoara }\end{array}$ & MG - Tiradentes & $\begin{array}{l}\text { PI - S.Raimundo } \\
\text { Nonato }\end{array}$ & RR - Boa Vista \\
\hline AL - Maragogi & CE - Nova Olinda & MS - Bonito & PI - Teresina & $\begin{array}{l}\text { RS - Bento } \\
\text { Gonçalves }\end{array}$ \\
\hline AM - Barcelos & DF - Brasília & MS - Campo Grande & PR - Curitiba & RS - Gramado \\
\hline AM - Manaus & ES - Vitória & MS - Corumbá & PR - Foz do Iguaçu & $\begin{array}{l}\text { RS - Porto } \\
\text { Alegre }\end{array}$ \\
\hline AM - Parintins & GO - Alto Paraíso & MT - Cáceres & PR - Paranaguá & $\begin{array}{l}\text { SC - Balneário } \\
\text { Camboriú }\end{array}$ \\
\hline AP - Macapá & GO - Caldas Novas & MT - Cuiabá & RJ - Angra dos Reis & $\begin{array}{l}\text { SC - Florianópo } \\
\text { lis }\end{array}$ \\
\hline BA - Lençóis & GO - Goiânia & PA - Belém & $\begin{array}{l}\text { RJ - Armação de } \\
\text { Búzios }\end{array}$ & SC - S.Joaquim \\
\hline BA - Maraú & GO - Pirenópolis & PA - Santarém & RJ - Paraty & SE - Aracaju \\
\hline $\begin{array}{l}\text { BA - Mata de } \\
\text { S.João }\end{array}$ & MA - Barreirinhas & PB - J. Pessoa & RJ - Petrópolis & SP - Ilhabela \\
\hline BA - Porto Seguro & MA - São Luís & $\begin{array}{l}\text { PE - Fernando de } \\
\text { Noronha }\end{array}$ & RJ - Rio de Janeiro & SP - São Paulo \\
\hline BA - Salvador & MG - Belo Horizonte & PE - Ipojuca & RN - Natal & TO - Mateiros \\
\hline CE - Aracati & MG - Diamantina & PE - Recife & RN - Tibau do Sul & TO - Palmas \\
\hline
\end{tabular}

Fonte: Estudo de Competitividade 65 Destinos Indutores (MINISTÉRIO DO TURISMO, 2008). 
Para a aferição da competitividade de destinos turísticos, foram utilizados os dados do Estudo de Competitividade do Ministério do Turismo realizado nos anos de 2008 e 2010 (MINISTÉRIO DO TURISMO, 2008; 2010). O Estudo avalia a competitividade a partir de treze dimensões, agrupadas em cinco macrodimensões, que contribuem para a formação de um índice de competitividade para cada destino (MINISTÉRIO DO TURISMO, 2008; 2010). As dimensões do estudo, assim como o índice de competitividade, são mensuradas em uma escala de 0 a 100 pontos. Para as análises do presente trabalho, foram considerados os valores das treze dimensões de competitividade para cada um dos 65 destinos estudados. A Figura 1 apresenta as dimensões que compõem cada uma das cinco macrodimensões.

Figura 1 - Macrodimensões e Dimensões do Estudo de Competitividade

\begin{tabular}{|c|c|c|}
\hline \multirow[t]{5}{*}{$\begin{array}{l}\text { Competitividade de } \\
\text { Destinos Turisticos Indutores }\end{array}$} & Infra-estrutura & $\begin{array}{l}\text { Infra-estrutura geral } \\
\text { Acesso }\end{array}$ \\
\hline & Turismo & $\begin{array}{l}\text { Serviços e equipamentos turisticos } \\
\text { Atrativos turisticos } \\
\text { Marketing }\end{array}$ \\
\hline & Politicas Públicas & $\begin{array}{l}\text { Politica pública } \\
\text { Cooperação regional } \\
\text { Monitoramento }\end{array}$ \\
\hline & Economia & $\begin{array}{l}\text { Economia local } \\
\text { Capacidade empresarial }\end{array}$ \\
\hline & Sustentabilidade & $\begin{array}{l}\text { Aspectos sociais } \\
\text { Aspectos ambientais } \\
\text { Aspectos culturais }\end{array}$ \\
\hline
\end{tabular}

Fonte: Ministério do Turismo (2008, p. 32).

Para aferição do desenvolvimento socioeconômico local, foram selecionadas as seguintes variáveis: número de empregos nas atividades características do turismo; salário médio dos empregos em atividades características do turismo; número de empresas nas atividades características do turismo; arrecadação de Imposto sobre Serviços - ISS, e Produto Interno Bruto per capita municipal. O Instituto Brasileiro de Geografia e Estatísticas - IBGE - define atividades econômicas características do turismo - ACT - como aquelas nas quais as unidades econômicas (as empresas) produzem pelo menos um produto característico de turismo, isto é, produtos sensíveis ao consumo de visitantes (IBGE, 2008). Dos doze grupos de atividades identificados pelo IBGE, foram considerados para o presente estudo apenas três: hotéis e similares, restaurantes e similares e agências de viagens e similares. A seleção desses grupos deve-se a sua maior identificação com a economia do turismo.

Os dados sobre arrecadação de ISS municipal e PIB per capita municipal foram obtidos a partir do sítio do IBGE (www.ibge.gov.br) e foram coletados entre os dias 16 e 25 de junho de 2012. Foram obtidos dados sobre PIB per capita municipal nos anos de 2007 e 2009, sendo esse o ano mais atualizado disponível. Não foram observados dados faltantes para a variável PIB per capita municipal. Para variável arrecadação de ISS municipal, foi possível obter dados referentes aos anos de 2007 e 2010. A variável arrecadação de ISS municipal, entretanto, apresentou dados faltantes para alguns destinos analisados.

Os dados sobre número de empregos, remuneração média e número de empresas nas ACT foram coletados a partir do banco de dados da Relação Anual de Informações Sociais - RAIS - do Ministério do Trabalho e Emprego. Foram coletadas informações referentes aos anos de 2007 e 2010. O acesso ao banco de dados foi possibilitado a partir de solicitação feita ao Programa de Disseminação de Estatísticas do Trabalho do Ministério do Trabalho e Emprego. A coleta ocorreu entre os dias 20 de junho e 15 de julho de 2012. 
Os dados sobre as diferentes ACT foram coletados seguindo a Classificação Nacional de Atividades Econômicas - CNAE, versão 2.0, no nível de agrupamento Classe. Dessa forma, foram utilizados os seguintes códigos: Hotéis e Similares - 55.10-8; Agências de Viagem - 79.11-2; e Restaurantes e outros estabelecimentos de serviços de alimentação e bebidas - 56.11-2. Os dados sobre número de empregos e remuneração média foram obtidos a partir do banco de dados da RAIS sobre vínculos e foram considerados os vínculos ativos em 31 de dezembro de cada ano. Para a coleta de dados sobre o número de estabelecimentos foi acessado o banco de dados da RAIS sobre empresas e foram desconsideradas as empresas que apresentaram declaração RAIS negativa por se tratarem de empresas que não possuem vínculos empregatícios.

Para realização das análises, foi utilizada a variação percentual dos fatores de competitividade entre os anos de 2008 e 2010 criados e a variação percentual das variáveis sobre número de empregos, salário médio dos empregados e número de empresas nas atividades características do turismo consideradas e arrecadação de ISS dos destinos turísticos entre os anos de 2007 e 2010. A utilização da variação percentual das variáveis ocasionou o achatamento da variância e a redução do número de casos que seriam considerados extremos. A variável PIB per capita apresenta valores até o ano de 2009 de forma que sua análise foi realizada à parte das demais variáveis dependentes. Destinos com variáveis com valor zero em variáveis no ano base de análise (2008 para as variáveis de competitividade e 2007 para as demais variáveis) foram considerados como valores faltantes.

A partir dos Fatores de Competitividade e dos Fatores de Desenvolvimento criados, procedeuse à limpeza do banco de dados. Nos Fatores de Competitividade foram identificados: um caso faltante no Fator Competitividade Turismo e cinco dados faltantes no Fator Competitividade Políticas Públicas. Adicionalmente foram identificados três casos extremos (acima de 3,29 desvios-padrão): um no Fator Competitividade Turismo, um no Fator Competitividade Políticas Públicas e um no Fator Competitividade Economia. Esses casos foram desconsiderados para as análises de regressão.

Os Fatores de Desenvolvimento Socioeconômico apresentaram dois casos faltantes no Fator Economia do Turismo, três casos faltantes no Fator Impactos Indiretos do Turismo, um caso faltante no Fator Remuneração da Economia do Turismo e seis casos faltantes no Fator Remuneração Serviços de Complementares. Não obstante foram identificados dois casos extremos no Fator Remuneração da Economia do Turismo e um caso extremo no Fator Remuneração Serviços Complementares. A variável PIB per capita, também utilizada como variável dependente, não possui casos faltantes, porém foi identificado um caso extremo. Casos faltantes e extremos em variáveis dependentes somente foram desconsiderados quando da utilização dessas variáveis. Com o banco limpo, foram realizadas as análises de regressão e de correlação. Foram empregadas a regressão stepwise com o método backward, bem como a regressão com o método entrada forçada. As análises de correlação foram realizadas a partir do coeficiente de correlação de Pearson. Para fins do presente estudo, será adotada a escala proposta por Field (2005) em que valores próximo de $\pm 0,1$ são considerados de fraca intensidade; valores próximos a $\pm 0,3$ são considerados de média intensidade e valores acima de $\pm 0,5$ são considerados de forte intensidade. Os resultados dessas análises são apresentados e discutidos na seção seguinte.

\section{RESULTADOS E ANÁLISE}

A análise fatorial foi empregada para a redução da quantidade de variáveis dependentes e independentes do estudo. A primeira análise fatorial foi realizada sobre os valores das dimensões de competividade mensuradas nos destinos turísticos no ano de 2008. Anterior à análise fatorial, foram aplicados os testes Kaiser-Meyer-Olkin - KMO - e de Esfericidade de Barlett para verificar se a análise fatorial era adequada. O resultado do teste $\mathrm{KMO}$ apresentou valor de 0,878 e o teste de Esfericidade de Barlett apresentou significância $(p<0,05)$, o que segundo Malhotra e Hair Jr. et al. (2009), respectivamente, indica que a análise fatorial é adequada.

O método de extração utilizado foi a análise do componente principal e o método de rotação foi o Varimax com normalização Kaiser, ambos padrão no software utilizado, por minimizar o número de variáveis com altas cargas sobre um fator, reforçando a interpretabilidade dos dados (MALHOTRA, 2001). Dimensões com coeficientes inferiores a 0,3 foram desprezadas na composição dos fatores. Os fatores gerados a partir da análise não foram passíveis de interpretação a partir do referencial 
teórico estudado, uma vez que diversas variáveis analisadas apresentaram coeficientes semelhantes em mais de um fator. A Tabela 1 apresenta os fatores gerados a partir das análises realizadas.

Tabela 1 - Fatores Gerados a partir das Dimensões de Competitividade

\begin{tabular}{l|l|l|l}
\hline \multirow{2}{*}{ Dimensões 2008} & Fatores* & 3 \\
\cline { 2 - 4 } & 1 & 2 & \\
\hline Infraestrutura &, 824 & & \\
\hline Acesso &, 840 & &, 383 \\
\hline Serviços e Equipamentos Turísticos &, 753 &, 318 &, 914 \\
\hline Atrativos Turísticos & & &, 500 \\
\hline Marketing &, 405 &, 435 & \\
\hline Políticas Públicas &, 450 &, 694 & \\
\hline Cooperação Regional & &, 791 &, 416 \\
\hline Monitoramento &, 390 &, 597 & \\
\hline Economia Local &, 809 & &, 305 \\
\hline Capacidade Empresarial &, 823 & & \\
\hline Aspectos Sociais &, 570 &, 510 &, 444 \\
\hline Aspectos Ambientais &, 318 &, 410 &, 470 \\
\hline Aspectos Culturais &, 530 & & \\
\hline
\end{tabular}

* Rotação convergida em 5 iterações.

De forma alternativa, tentou-se a análise fatorial a partir da variação em valores absolutos dos valores das treze dimensões de competitividade. Dessa forma, para cada uma das dimensões de competitividade dos destinos turísticos foi criada uma nova variável a partir da subtração do valor da competitividade no ano de 2010 pelo valor da competitividade no ano de 2008. A análise fatorial da variação das dimensões da competitividade entre os anos de 2008 e 2010 apresentaram valor para o teste KMO de 0,486, e o teste de Esfericidade de Barlett não apresentou valores significativos, o que, seguindo o padrão proposto por Malhotra (2001), indica que a análise fatorial seria inapropriada.

Considerando os resultados da análise fatorial com as dimensões de competitividade do modelo do Ministério do Turismo (2008), havendo dimensões com cargas fatoriais próximas em mais de um fator, além de dimensões com cargas fatoriais baixas para todos os fatores estatísticos criados, pode-se questionar a composição das macrodimensões do Modelo, assim como a pertinência de algumas de suas dimensões para a avaliação da competitividade de destinos turísticos.

Em face da impossibilidade de se alcançar fatores estatísticos, optou-se pelo estabelecimento de fatores teóricos, tomando por base a descrição do comportamento das diferentes dimensões de competitividade proporcionada pelo próprio modelo do Ministério do Turismo (2008). Não foi possível, no entanto, identificar no referido modelo o peso das dimensões para a composição das macrodimensões ou do índice de competitividade. Como forma de obter fatores para análise, estabeleceu-se que cada macrodimensão representaria um fator de competitividade e que seu valor seria dado pela média dos valores das dimensões que o compõem. O Quadro 2 apresenta os Fatores teóricos criados. Para realização das análises, foi considerada a variação percentual dos valores aferidos para os fatores entre os anos de 2010 e 2008.

Quadro 2 - Fatores Teóricos criados a partir das Dimensões de Competitividade

\begin{tabular}{|l|l|}
\hline Fatores de Competitividade & Dimensões \\
\hline \multirow{2}{*}{ Infraestrutura } & Infraestrutura Geral \\
& Acesso \\
\hline
\end{tabular}




\begin{tabular}{|c|c|}
\hline Turismo & $\begin{array}{l}\text { Serviços e Equipamentos Turísticos } \\
\text { Atrativos Turísticos } \\
\text { Marketing }\end{array}$ \\
\hline Políticas Públicas & $\begin{array}{l}\text { Política Pública } \\
\text { Cooperação Regional } \\
\text { Monitoramento }\end{array}$ \\
\hline Economia & $\begin{array}{l}\text { Economia Local } \\
\text { Capacidade Empresarial }\end{array}$ \\
\hline Sustentabilidade & $\begin{array}{l}\text { Aspectos Sociais } \\
\text { Aspectos Ambientais } \\
\text { Aspectos Culturais }\end{array}$ \\
\hline
\end{tabular}

Fonte: Estudo de Competitividade 65 Destinos Indutores (MINISTÉRIO DO TURISMO, 2008, p. 32).

A análise fatorial também foi empregada sobre as variáveis de desenvolvimento seguindo as mesmas condições anteriormente citadas. Para essa segunda análise, o teste KMO apresentou resultado 0,502 e o Teste de Esfericidade de Barlett apresentou valores significativos, o que demonstra que a análise fatorial é adequada de acordo com os padrões descritos por Malhotra (2001). A Tabela 2 apresenta os Fatores resultantes da análise. As variáveis com coeficientes fatoriais a 0,5 foram desprezadas na composição dos fatores.

Tabela 2 - Fatores Gerados - Variáveis Desenvolvimento Socioeconômico

\begin{tabular}{l|l|l|l|l}
\hline \multirow{2}{*}{ Variáveis } & \multicolumn{2}{c}{ Fatores* } & 3 & 4 \\
\cline { 2 - 5 } & 1 & 2 & & \\
\hline$\Delta \%$ No Hotéis &, 895 & & & \\
\hline$\Delta \%$ No Agências &, 725 & & & \\
\hline$\Delta \% N^{\circ}$ Empregos Hotéis &, 804 & & & \\
\hline$\Delta \%$ Arrecadação de ISS & &, 570 & & \\
\hline$\Delta \%$ No Restaurantes & &, 884 & & \\
\hline$\Delta \%$ No Empregos Restaurantes & &, 924 & & \\
\hline$\Delta \%$ Remuneração Média Restaurantes & & &, 762 & \\
\hline$\Delta \%$ Remuneração Média Hotéis & & & &, 784 \\
\hline$\Delta \%$ Remuneração Média Agências & & & &, 565 \\
\hline$\Delta \%$ No Empregos Agências & & & & \\
\hline
\end{tabular}

*Rotação convergida em 5 iterações.

As informações constantes da Tabela 2 demonstram que foram criados quatro fatores. Destacase que as variáveis Arrecadação de ISS, Remuneração Média de Restaurantes e Número de Agências de Viagens apresentaram cargas relevantes em mais de um fator. Devido à diferença nos valores das cargas, optou-se pela manutenção das variáveis nos fatores em que elas possuíssem maior carregamento e por desconsiderar sua presença nos fatores de menor carregamento para o prosseguimento das análises. 
O Fator 1 foi denominado de Economia do Turismo - ECOT - e engloba as variáveis: número de empregos em hotéis, número de hotéis e número de agências de viagens. O Fator 2 foi denominado Impactos Indiretos do Turismo - IMPT - e englobou as variáveis arrecadação de ISS, número de empregos em restaurantes e número de restaurantes. As duas ACT que mais empregam na economia do turismo (meios de hospedagem e restaurantes) estão incluídas no Fator 3, designado Remuneração da Economia do Turismo - REMT. Por fim, o Fator 4 envolve o número de empregos e a remuneração média dos empregados de agências de viagens e foi denominado Remuneração Serviços Complementares - REMC. Como forma de possibilitar a efetiva redução das variáveis dependentes, os fatores criados foram transformados em valores a partir dos coeficientes fatoriais atribuídos às variáveis que os compõem.

As análises de regressão empregaram os Fatores de Competitividade como variáveis independentes e os Fatores de Desenvolvimento Socioeconômico e o PIB per capita como variáveis dependentes. Apenas uma das análises de regressão não apresentou significância estatística para os Fatores de Competitividade. Todas as demais regressões apresentaram significância estatística em que os modelos resultantes contam apenas com uma variável independente. A Tabela 3 resume os resultados das análises de regressão.

Tabela 3 - Resumo dos Resultados Análises de Regressão

\begin{tabular}{|c|c|c|c|c|c|c|c|}
\hline \multirow{2}{*}{$\begin{array}{c}\text { Variável } \\
\text { Dependente }\end{array}$} & \multirow{2}{*}{$\begin{array}{c}\text { Variável } \\
\text { Independente }\end{array}$} & \multirow{2}{*}{ Modelos } & \multicolumn{2}{|c|}{$\begin{array}{c}\text { Coeficientes não } \\
\text { Padronizados }\end{array}$} & \multirow{2}{*}{$\begin{array}{c}\begin{array}{c}\text { Coeficientes } \\
\text { Padroniza- } \\
\text { dos }\end{array} \\
\text { Beta }\end{array}$} & \multirow{2}{*}{$\mathrm{T}$} & \multirow{2}{*}{ Sig. } \\
\hline & & & B & $\begin{array}{c}\text { Erro } \\
\text { Padrão }\end{array}$ & & & \\
\hline \multirow{2}{*}{ Fator ECOT } & \multirow{2}{*}{ Fator Comp. Turismo } & (Constante) & 12,684 & 5,227 & & 2,427 & 0,019 \\
\hline & & F.CTurismo & 0,796 & 0,267 & 0,379 & 2,979 & 0,004 \\
\hline \multirow{2}{*}{ Fator IMPT } & \multirow{2}{*}{ Fator Comp. Turismo } & (Constante) & 29,372 & 3,886 & & 7,559 & 0 \\
\hline & & F.CTurismo & 0,728 & 0,196 & 0,458 & 3,713 & 0,001 \\
\hline \multirow{2}{*}{ Fator REMT } & \multirow{2}{*}{$\begin{array}{l}\text { Fator Comp. Políticas } \\
\text { Públicas }\end{array}$} & (Constante) & 40,814 & 1,415 & & 28,841 & 0 \\
\hline & & F.CPolPúb & 0,114 & 0,047 & 0,322 & 2,449 & 0,018 \\
\hline Fator REMC & - & (Constante) & 41,727 & 6,095 & & 6,846 & 0 \\
\hline \multirow{2}{*}{ PIB per capita } & \multirow{2}{*}{$\begin{array}{l}\text { Fator Comp. In- } \\
\text { fraestrutura }\end{array}$} & (Constante) & 9,333 & 3,511 & & 2,658 & 0,01 \\
\hline & & F.CInfra & 1,079 & 0,437 & 0,319 & 2,472 & 0,017 \\
\hline
\end{tabular}

Os resultados das análises de regressão indicam que o Fator Competitividade Turismo possui influência significativa sobre os Fatores ECOT e IMPT. O Fator Competitividade Políticas Públicas teria influência significativa sobre o Fator REMT. O PIB per capita dos destinos seria influenciado pelo Fator Competitividade Infraestrutura. A única variável independente que não apresentou significância estatística foi o Fator REMC. A significância do Fator Competitividade Turismo com dois Fatores de desenvolvimento indica que esse seria o Fator de Competitividade mais importante para o desenvolvimento dos destinos turísticos estudados. Os Fatores de Desenvolvimento que figuram como variáveis dependentes do Fator Competitividade Turismo são compostos por variáveis relacionadas ao número de empreendimentos e ao número de empregos gerados em ACT, o que reforça sua importância para o desenvolvimento da economia do turismo nos destinos turísticos.

O Fator Competitividade Políticas Públicas apresentou significância estatística na análise de regressão do Fator REMT. Ao examinar a composição dos fatores, observa-se que o Fator Competitividade Políticas Públicas seria o único com influência sobre a remuneração das atividades características do turismo. Uma possível explicação para o relacionamento positivo entre os dois Fatores seria a presença de políticas públicas que ordenariam e regulamentariam o setor, além de prover a capacitação e a qualificação necessárias para a competitividade dos destinos turísticos. 
As análises de regressão com PIB per capita apresentaram significância estatística para o Fator Competitividade Infraestrutura. A variação do PIB per capita é um indicador de desenvolvimento da renda da população dos destinos e um indicador indireto da evolução da economia do turismo, o que permite inferir a influência da infraestrutura no desenvolvimento da renda local.

As variáveis PIB per capita, número de empregos e remuneração média das ACT são variáveis que tratam do efeito do turismo na economia dos destinos. Os resultados evidenciam que, para que o desenvolvimento da competitividade possa ter efeitos positivos, não basta que fatores relacionados estritamente às atividades turísticas estejam desenvolvidos. É necessária também a presença de políticas públicas e da infraestrutura para que o desenvolvimento do turismo tenha reflexos para a população local. Esses resultados demonstram que diferentes fatores de competitividade influenciariam diferentes aspectos do desenvolvimento, o que reforça a necessidade de uma perspectiva sistêmica para análise da competitividade.

Os Fatores de Competitividade Economia e Sustentabilidade não apresentaram correlação com quaisquer Fatores de Desenvolvimento, o que denota serem Fatores comparativamente menos importantes para explicar o desenvolvimento socioeconômico nos destinos turísticos estudados. No primeiro caso, o Fator é composto pelas dimensões Capacidade Empresarial e Economia Local, o que, para Ritchie e Crouch (2010), estaria associado aos ambientes macro e micro em que o destino turístico se insere e que também guarda relação com as forças competitivas identificadas por Porter (1986). Considerando que as análises foram realizadas a partir da variação dos fatores, é de se esperar que indicadores sobre a capacidade empresarial, assim como sobre a economia local, se mantivessem constantes dado o curto período considerado. Ainda assim, essa dimensão não se mostrou significativa para o desenvolvimento da competitividade no período analisado.

No tocante ao Fator Competitividade Sustentabilidade, embora a composição do Fator denote uma acepção ampla do termo sustentabilidade (incluindo as dimensões Aspectos Sociais, Aspectos Ambientais e Aspectos Culturais), o Fator não se mostrou significativo no desenvolvimento dos Fatores de Desenvolvimento Socioeconômico. Considerando a perspectiva de que a competitividade sem sustentabilidade seja efêmera, conforme defendido de forma mais ativa por Hassan (2000) e Mazaro (2007), era de se esperar que tais aspectos fossem significativos para o desenvolvimento dos destinos turísticos estudados. A ausência de significância, no entanto, pode ser explicada pela temporalidade do estudo. $O$ intervalo de tempo considerado pode não ter sido suficiente para que a sustentabilidade manifestasse seus efeitos, sendo a degradação ou a conservação de seus ativos sentido no médio ou longo prazos. Dessa forma, pode-se compreender a sustentabilidade não como um Fator que gere o desenvolvimento socioeconômico, mas como uma condição necessária para sua manutenção.

Observa-se que o número de variáveis e dimensões que compõe os Fatores torna difícil a identificação dos pesos existentes nas relações. Dessa forma, para complementar as análises de regressão, foram realizadas análises de correlação com as variáveis que compõem os Fatores, considerados apenas aqueles que apresentaram significância estatística em suas análises de regressão. A Tabela 4 apresenta os resultados das análises de correlação de Pearson com significância estatística.

Tabela 4 - Resumo Análises de Correlação Significativas

\begin{tabular}{l|l|l}
\hline $\begin{array}{l}\text { Dimensões de Competi- } \\
\text { tividade }\end{array}$ & Variáveis Desenvolvimento & $\begin{array}{l}\text { Coeficiente de Correlação de } \\
\text { Pearson }\end{array}$ \\
\hline \multirow{2}{*}{$\begin{array}{l}\text { Serviços e Equipamentos } \\
\text { Turísticos }\end{array}$} & Número de Hotéis & 0,305 \\
\cline { 2 - 3 } & Número de Agências de Viagens & 0,288 \\
\cline { 2 - 3 } & Número de Empregos Restaurantes & 0,396 \\
\hline \multirow{2}{*}{ Marketing } & Número de Empregos em Hotéis & 0,348 \\
\cline { 2 - 3 } & Número de Hotéis & 0,399 \\
\cline { 2 - 3 } & Arrecadação de ISS & 0,427 \\
\hline Política Pública & Remuneração Média em Hotéis & $-0,317$ \\
\hline Monitoramento & Remuneração Média em Hotéis & 0,292 \\
\hline Acesso & PIB per capita & 0,296 \\
\hline
\end{tabular}


Os resultados da análise de correlação indicam que existe correlação de intensidade média entre a dimensão de competitividade Marketing e o número de hotéis e o número de empregos em hotéis. A dimensão Serviços e Equipamentos Turísticos apresentou correlação de intensidade média com as variáveis Número de Hotéis e Número de Agências de Viagens. As ações de marketing estão normalmente voltadas para promoção, comercialização e posicionamento do destino no mercado e são entendidas como ações relacionadas à gestão do destino (DWYER; KIM, 2003; RITCHIE; CROUCH, 2010). A dimensão Serviços e Equipamentos considera os serviços privados ofertados aos turistas e os equipamentos existentes para o receptivo e suporte ao desenvolvimento da atividade turística em termos de sua qualidade e disponibilidade (MINISTÉRIO DO TURISMO, 2008). Ritchie e Crouch (2010) destacam ainda a necessidade de um microambiente competitivo em que as organizações possam se desenvolver. Dessa forma, quanto maior o número de organizações interagindo, seja via competição ou cooperação, melhor a competitividade e melhores os serviços prestados.

A dimensão Atrativos, também inserida no Fator Competitividade Turismo, não apresentou correlação significativa com as variáveis que compõem os Fatores ECOT e IMPT. Por envolver principalmente atrativos naturais e culturais (MINISTÉRIO DO TURISMO, 2008), a dimensão Atrativos relaciona-se a aspectos inatos e idiossincráticos dos destinos turísticos e, portanto são de difícil desenvolvimento e imitação e apresentariam pouca variação no tempo, o que explicaria a não correlação estatística com o desenvolvimento socioeconômico dos destinos. Embora essas características coincidam com os atributos de um recurso capaz de gerar vantagens competitivas, Barney (1991), Crouch e Ritchie (1999) ressaltam que os atrativos naturais e culturais relacionam-se com a vantagem comparativa dos destinos. Hassan (2000) destaca que os destinos turísticos devem explorar suas vantagens comparativas únicas de forma a se mostrar atrativo para um determinado segmento. Dessa forma, a vantagem competitiva seria alcançada a partir da habilidade do destino em empregar efetivamente seus recursos. O modelo VRIO de Barney e Hesterly (2011) estabelece que os recursos, para que gerem vantagem competitiva sustentável, devem ser valiosos, raros, de difícil imitação, além de serem empregados de forma correta pela organização. Nesse sentido, as ações de marketing ou o desenvolvimento de serviços e equipamentos são entendidas como atividades de gestão do destino (CROUCH; RITCHIE, 1999; DWYER; KIM, 2003; RITCHIE; CROUCH, 2010) que possibilitam o emprego de seus recursos inatos, agregam valor à experiência ofertada e transformam a vantagem comparativa do destino em vantagens competitivas.

A dimensão de competitividade Política Pública apresenta coeficiente de correlação negativo com intensidade média para a variável Remuneração Média em Hotéis. Segundo o Estudo de Competitividade (MINISTÉRIO DO TURISMO, 2008), a dimensão Políticas Públicas engloba, entre suas variáveis: estrutura municipal para apoio ao turismo, grau de cooperação com o governo estadual, grau de cooperação com o governo federal, planejamento para a cidade e para a atividade turística e grau de cooperação público-privada. Nota-se que Dwyer e Kim (2003), assim como Crouch e Ritchie (1999), não abordam diretamente a questão de políticas públicas para o desenvolvimento da competitividade. Ainda assim, seus modelos ressaltam o papel da gestão tanto pública quanto privada para o desempenho dos destinos turísticos. Embora a expectativa fosse de que houvesse correlação positiva entre a dimensão e a variável, o resultado permite inferir um comportamento inversamente proporcional, ou seja, a variação positiva da dimensão política pública seria acompanhada da variação negativa da remuneração dos empregados de meios de hospedagem. O Modelo Sistêmico e os principais modelos de competitividade de destinos turísticos ressaltam a importância do planejamento e da coordenação entre as organizações (públicas e privadas) e os stakeholders envolvidos no desenvolvimento da atividade turística (ESSER et al., 1996; CROUCH; RITCHIE, 1999; RITCHIE; CROUCH, 2010; DWYER; KIM, 2003). Essa preocupação também se mostra presente no modelo do MTur (2008), de forma que a correlação negativa pode evidenciar problemas em algum desses aspectos inerentes à política pública de turismo.

Reforçando o argumento proposto, a dimensão Monitoramento apresentou correlação positiva também com intensidade média com a variável Remuneração Média em Hotéis. A dimensão Monitoramento engloba, entre outras variáveis, a realização de pesquisas de demanda e de oferta, a existência de sistemas de estatísticas de turismo e o monitoramento dos impactos do turismo. 0 monitoramento possibilitaria aos destinos uma melhor percepção das variações dos aspectos macro e microambientais descritos por Crouch e Ritchie (1999) e sua adequada reação aos desafios interpostos pela concorrência. O desenvolvimento de um sistema de monitoramento efetivo demanda tempo e recursos, não sendo de fácil replicação pela concorrência. Essas características são destacadas por 
Dierickx e Cool (1989) e por Barney como diferenciais competitivos que possibilitam a geração de vantagem competitiva sustentável. Dessa forma, pode-se inferir que, para os destinos estudados, a presença de monitoramento seria um recurso distintivo que possibilitaria a geração de políticas públicas mais adequadas aos desafios do ambiente em que os destinos turísticos se inserem.

Os resultados da análise de correlação apontam que o PIB per capita apresenta uma correlação de intensidade média com a variável Competitividade Acesso, porém não apresenta correlação estatística significativa com a dimensão Infraestrutura Geral (que também compõe o Fator Infraestrutura). Os modelos de competitividade normalmente posicionam a infraestrutura geral (abastecimento de água, saneamento básico, energia elétrica, telecomunicações, entre outros) e o acesso (portos, aeroportos, rodovias, sinalização) entre as variáveis relacionadas aos fatores ou aos recursos de suporte necessários para a competitividade dos destinos turísticos (CROUCH; RITCHIE, 1999; DWYER; KIM, 2003; GOOROOCHURN; SUGIYARTO, 2004), sem, no entanto, diferenciar ou distinguir os efeitos específicos relacionados a cada tipo de infraestrutura. Embora diversos tipos de infraestrutura contribuam para a competitividade turística, os resultados apontam que somente as infraestruturas de acesso seriam influentes para o aumento da renda nos destinos estudados.

Taberner (2007) identifica entre as principais limitações dos modelos de competitividade a alta de uma ordem de importância entre os componentes e as variáveis que os compõem. A partir dos resultados das análises de regressão e de correlação, podem-se identificar quais dimensões de competitividade foram mais influentes para o desenvolvimento local. Ao observar as dimensões de competitividade mais influentes, nota-se que boa parte dessas dimensões (Serviços e Equipamentos Turísticos, Marketing e Monitoramento) está diretamente associada à gestão dos destinos turístico nos modelos de Dwyer e Kim (2003) e de Ritchie e Crouch (2010). Nesse sentido, embora os dois modelos mais referenciados sejam exaustivos ao identificar os aspectos envolvidos na competitividade de destinos turísticos, conforme aponta Mazaro (2007), pode-se argumentar que, para os destinos turísticos nacionais estudados, há uma centralidade dos aspectos associados à gestão dos destinos para a geração de retornos positivos para a sociedade.

Considerando os quatro níveis de análise do Modelo de Competitividade Sistêmica de Esser et al. (1986), os resultados indicam uma preponderância do nível meso (relacionado a fatores capazes de gerar em entorno apto a fomentar, multiplicar e os esforços das empresas) para o desenvolvimento de destinos turísticos. Os níveis macro e micro estariam associados ao ambiente em que os destinos turísticos se inserem. Conforme verificado, embora essas características sejam importantes para a competitividade, não apresentaram relação direta com o desenvolvimento econômico dos destinos estudados. O nível meta, por fim, aborda os aspectos de integração necessários para o desenvolvimento da competitividade. Considerando os resultados da dimensão Política Pública que trata, entre outros aspectos da integração, das ações locais com a atuação dos governos estadual e federal, essa deveria ser uma dimensão observada com maior cuidado para a geração de benefícios a partir do desenvolvimento da competitividade.

\section{CONCLUSÃO}

O presente trabalho teve por objetivo analisar a relação entre a competitividade de destinos turísticos e o desenvolvimento local e identificar as dimensões da competitividade que são influentes para o desenvolvimento dos destinos turísticos. Adicionalmente buscou-se identificar quais dimensões da competitividade são mais influentes para o desenvolvimento dos destinos turísticos.

Os resultados demonstram que o Fator Competitividade Turismo, por possuir significância estatística sobre um maior número de Fatores de Desenvolvimento Socioeconômico, seria o Fator de Competitividade mais influente. Análises complementares entre as variáveis e as dimensões que compõem os fatores indicam que as dimensões Marketing e Serviços e Equipamentos Turísticos possuem correlação significativa com as variáveis de desenvolvimento socioeconômico selecionadas para o presente estudo. Essas dimensões estão relacionadas à gestão dos destinos turísticos nos modelos de Crouch e Ritchie (1999), Dwyer e Kim (2003) e Ritchie e Crouch (2010), o que indica que a gestão dos destinos turísticos seria o principal aspecto a ser considerado para o desenvolvimento da competitividade de destinos turísticos. Isso talvez explique a razão pela qual diversos destinos turísticos, ainda que dotados de recursos e atrativos naturais e culturais, não consigam desenvolver o turismo. 
Retomando a indagação proposta por Crouch (2011), de que o próximo passo no desenvolvimento dos modelos de competitividade de destinos turísticos seria a identificação de atributos determinantes para a competitividade, os resultados ora apresentados permitem distinguir quais dimensões foram mais importantes, considerando como critério para análise a influência sobre variáveis de desenvolvimento socioeconômico. De forma, complementar os resultados indica ainda que diferentes dimensões influenciam diferentes variáveis de desenvolvimento, o que corrobora a importância de uma perspectiva sistêmica para a análise da competitividade de destinos turísticos.

Ao retomar o argumento de que a competitividade dos destinos turísticos não é o objetivo final a ser perseguido, mas uma meta intermediária para o desenvolvimento econômico e social dos destinos turísticos (CROUCH; RITCHIE, 1999; DWYER; KIM, 2003), os resultados da pesquisa permitem avaliar o Modelo Brasileiro utilizado pelo Ministério do Turismo (2008; 2010). Os resultados das análises fatoriais com as dimensões não se aproximam das macrodimensões de competitividade proposta pelo Modelo, havendo dimensões com cargas fatoriais próximas em mais de um fator, além de dimensões com cargas fatoriais baixas para todos os fatores estatísticos criados. As análises de regressão com os fatores teóricos demonstram que nem todos os fatores possuem correlação com as variáveis de desenvolvimento selecionadas. Dessa forma, pode-se questionar a composição das macrodimensões do Modelo e a pertinência de algumas de suas dimensões.

Entre as principais limitações do presente estudo, pode-se citar o curto intervalo de tempo entre os fenômenos estudados. Em que pese os achados poderem ser compreendidos como resultados de curto ou médio prazos, os efeitos descritos nos modelos de competitividade de destinos turísticos (desenvolvimento social e econômico) podem demandar mais tempo para se manifestarem de forma plena. A relação entre competitividade e desenvolvimento socioeconômico pode não ser imediata. Partindo dessas considerações, sugere-se a continuidade do acompanhamento da competitividade dos destinos turísticos em paralelo aos indicadores de desenvolvimento durante um prazo mais longo para aferir de forma mais clara a relação entre as variáveis e os fatores, além de verificar a influência de aspectos ambientais e da sustentabilidade para o desenvolvimento da competitividade.

\section{REFERÊNCIAS}

BARNEY, J.B. Firm Resources and Sustained Competitive Advantage. Journal of Management, v. 17, p. 99-120, 1991.

BARNEY, J.B.; HESTERLY, W. S. Administração Estratégica e Vantagem Competitiva. 3. ed. São Paulo: Pearson Prentice Hall, 2011.

BERTERO, C.; VASCONCELOS, F.; BINDER, M. Estratégia Empresarial: a Produção Científica Brasileira entre 1991e 2001. RAE, v. 43, n. 4, p. 48-62, 2003.

BUHALIS, D. Marketing the competitive destination of the future. Tourism Management, $N^{\circ} 21$, p. 97 $-116,2000$.

CAMPBELL-HUNT, C. What have we learned about generic competitive strategy? A meta-analysis. Strategic Management Journal, 21, p.127-154, 2000.

CARNeiRo, J.M.T.; CAVAlCANTI, M. A. F. D.; SilVA, J. F. Porter Revisado: Análise Crítica da Tipologia Estratégica do Mestre. Revista de Administração Contemporânea, v. 1, n. 3, p. 7-30, 1997.

COSTA, H. A.; HOFFMANN, V. E. Competitividade de Destinações Turísticas. Turismo em Análise, v.17, n. 2, p. 113-134, 2006.

COYNE, K. P. Sustainable competitive advantage: What It Is, What it Isn't. Business Horizons, jan/ fev. 1986

CROUCH, G. I. Destination Competitiveness: An Analysis of Determinant Attributes. Journal of Travel Research, 50(1) $27-45$, SAGE Publications, 2011.

CROUCH, G. I. ; RITCHIE, J. R. B. Tourism, Competitiveness, and Societal Prosperity. Journal of Business Research, vol. 44, n. 3, p. 137-152, 1999.

DIERICKX, I.; COOL, K. Asset stock accumulation and sustainability of competitive advantage. Management Science. v. 33, n. 12, dez. 1989. 
DWYER, L.; KIM, C. Destination Competitiveness: Determinants and Indicators. Current Issues in Tourism, v.6, n.5, 2003.

ESSER, K.; HILLEBRAND, W.; MESSNER, D. ; MYER-STAMER, J. Competitividad Sistémica: Nuevo Desafío... Revista de la Cepal, n. 59, p. 39-52, 1996.

FIELD, A. Discovering Statistics using SPSS. 2. ed. London: Sage Publications, 2005.

FÓRUM ECONÔMICO MUNDIAL. The Travel and Tourism Competitiveness Report 2011. Geneva, Suíça, 2011.

FURRER, O.; THOMAS, H.; GOUSSEVSKAIA, A. The structure and evolution of the strategic management field: a content analysis of 26 years of strategic management research. International Journal of Management Reviews, v. 10. n. 1, p. 1-23, 2008.

GOOROOCHURN, N.; SUGIYARTO, N. Measuring Competitiveness in the travel and tourism industry. Discussion Paper - TTRI. Nottingham University Business School, Nottingham. University of Nottingham, 2004.

GRANT, R. M. The Resource-Based Theory of Competitive Advantage: Implications for Strategy Formulation. California Management Review, p.114-135, Spring 1991.

HAIR JR., J. F., BLACK, W. C., BABIN, B. J., ANDERSON, R. E. Multivariate Data Analisys. 7. ed. Prentice Hall, 2009.

HASSAN, S. S. Determinants of Market Competitiveness in an Environmentally Sustainable Tourism Industry. Journal of Travel Research, Vol. 38, p. 239-245, 2000.

HEATH, E. Towards a Model to Enhance Destination Competitiveness: A Southern African Perspective. Journal of Hospitality and Tourism Management, 10(2), p. 124-141, 2003.

HOFFMAN, Nicole P. An examination of the "Sustainable competitive advantage" concept: past, present, and future. Academy of Marketing Science Review, n. 4, p. 1-16, 2000

HOFFMANN, V. E.; COSTA, H. A.; BATAGLIA, W. Systemic Competitiveness in Tourism. In: EURAM - European Academy of Management, Roma. Anais do EURAM, 2010.

INSTITUTO BRASILEIRO DE GEOGRAFIA E ESTATÍSTICAS - IBGE. Economia do Turismo: uma perspective macroeconômica. Estudos e Pesquisas Informação Econômica número 7, Rio de Janeiro, 2008.

MALHOTRA, N. K. Pesquisa de Marketing: uma orientação aplicada. 3. ed. Porto Alegre: Bookman, 2001.

MAZARO, R.M. Factores determinantes de competitividad para destinos turísticos en el marco de la sostenibilidad. Observatório de Inovação do Turismo, Volume II, Número 1, Março de 2007.

MEYER-STAMER, J. Estratégias de Desenvolvimento Local e Regional: Cluster, Política de Localização e Competitividade Sistêmica. Friedrich Ebert Stiftung, Policy Paper, n. 28, 2001.

MINISTÉRIO DO TURISMO; SEBRAE; FUNDAÇÃO GETULIO VARGAS; BARBOSA, L. G. (org.). Estudo de Competitividade dos 65 Destinos Indutores do Desenvolvimento Turístico Regional - Relatório Brasil. Brasília - DF, 2008.

PETERAF, M. The cornerstones of competitive advantage: a resource-based view. Strategic Management Journal, v. 14. p. 179-191, 1993.

PORTER, M. Estratégia Competitiva. São Paulo: Campus, Capítulos 1 e 2, 1986.

RITCHIE, J.R.B.; CROUCH, G. I. A Model of Destination Competitiveness/ Sustainability: Brazilian perspectives. Revista de Administração Pública - RAP, Rio de Janeiro, 44(5), p. 1049-66, 2010.

TABERNER, J. G. Propuesta de dos Índices para la Medición de la Competitividad de los Destinos de sol y playa del Mediterrâneo. Revista de Análisis Turístico, no 4, $2^{\circ}$ semestre 2007, pp. 50-67.

TEECE, D. J.; PISANO, G.; SHUEN, A. Dynamic Capabilities and Strategic Management. Strategic Management Journal, v. 18, p. 509-533, 1997.

VASCONCELOS, F. C.; CYRINO, A. B.; Vantagem Competitiva. Revista de Administração de Empresas - RAE, n. 4, 2000.

WERNERFELT, B. A Resource-based View of the Firm. Strategic Management Journal, Vol. 5, No 2, pp. 171-180, 1984. 